\title{
Urban sound energy reduction by means of sound barriers
}

\author{
Vlad Iordache* and Mihai Vlad Ionita \\ Research Center CAMBI, Technical University of Civil Engineering of Bucharest, Romania
}

\begin{abstract}
In urban environment, various heating ventilation and air conditioning appliances designed to maintain indoor comfort become urban acoustic pollution vectors due to the sound energy produced by these equipment. The acoustic barriers are the recommended method for the sound energy reduction in urban environment. The current sizing method of these acoustic barriers is too difficult and it is not practical for any $3 D$ location of the noisy equipment and reception point. In this study we will develop based on the same method a new simplified tool for acoustic barriers sizing, maintaining the same precision characteristic to the classical method. Abacuses for acoustic barriers sizing are built that can be used for different $3 D$ locations of the source and the reception points, for several frequencies and several acoustic barrier heights. The study case presented in the article represents a confirmation for the rapidity and ease of use of these abacuses in the design of the acoustic barriers.
\end{abstract}

\section{Introduction}

The noise protection represents today one of the main design requirements in order to meet international LEED and BREAM standards as well as the Romanian Ministry of Development design option F requirement. Today, several types of building services equipment (chillers, heat pumps, compressor, VRVs, Rooftops, and others) alongside their role in preserving the indoor comfort of the serviced building, they become sound pollution vectors and sometimes leading to the violation of the noise protection requirements in urban environment [1]

The sound energy emitted by the equipment in the environment and leads to an increase of the acoustic pressure above the background value. The higher the acoustic pressure in a specific reception point the higher the sound energy arrived in that reception point. The amount of energy arrived at the reception point depends on the length of the sound wave propagation path: the further the reception point, the smaller the energy arrived, the smaller the acoustic pressure and finally the smaller the acoustic pressure level.

Therefore, engineers and architects strive to find solutions to reduce the sound energy arrived at specific locations in the urban environment and consequently reduce the noise level at that location. The installation acoustic barriers in-between the noise generation equipment and the reception point represents a noise protection solution. The design of these acoustic barriers consists in determining the position, length and height of this acoustic barrier. The height of the acoustic barrier is a design element that is most often done using the Maekawa diagram [2]. Although, other theories have been developed depending on the type of relief, the shape of the acoustic barrier [3], its thickness or the presence of an inclined cover [4] [5] as well as the type of noise source (point or line) [6], however Makawa Diagram remains today the most widely used method.
This acoustic barrier sizing procedure based on Maekawa's theory represents a method hardly exploitable by engineers and architects due to the complexity of calculations required to be performed for the entire spectrum according to national noise protection requirements [7]. In this study we propose a new and simplified method for the sizing of an acoustic barrier, method based on the same theory. This new design tool will lead, in a faster and easier way, to the same results. Today there are no simplified calculation abacuses for this sizing procedure neither in international norms nor in research literature. The aim of this study is to produce several abacuses in order to rapidly determine the correct height for these acoustic barriers. These abacuses should be relevant to different 3D geometries and different locations of the reception point (that is intended to be protected).

The paper presents the method for the construction of the abacus for the rapid calculation of acoustic barrier for all frequencies and a study case that aims to understand the applicability and the ease of the new design method.

\section{Method}

In this paragraph we will present the analyzed geometry and the method used for the construction of the calculation abacus for fast noise level decrease.

The analyzed geometry at urban level (Fig. 1) consists of three different elements:

- a noise source (chiller, pump, fan or other noisy equipment) that will be considered in our analysis as a stationary noise source, placed at $1 \mathrm{~m}$ above the ground;

- an acoustic barrier located at $1 \mathrm{~m}$ away from the noise source. Its height is from the ground level up to the design height. Such an acoustic barrier should exceed the altitude of the noise source. In this study we aim to examine five different heights for the acoustic barrier:

\footnotetext{
* Corresponding author: viordach@yahoo.com
} 
a) $1 \mathrm{~m}$ representing the lower limit, b) $2 \mathrm{~m}$, c) $3 \mathrm{~m}$, d) $4 \mathrm{~m}$ and e) $5 \mathrm{~m}$. From a structural viewpoint, the barrier has a specific mass greater than $10 \mathrm{~kg} / \mathrm{m}^{2}$, so that the main sound wave is the diffracted wave (the wave passing around the acoustic barrier) and not the wave perpendicular on the acoustic barrier crossing the barrier.

- the area protected by the acoustic barrier is the area behind this acoustic barrier that is not directly visible

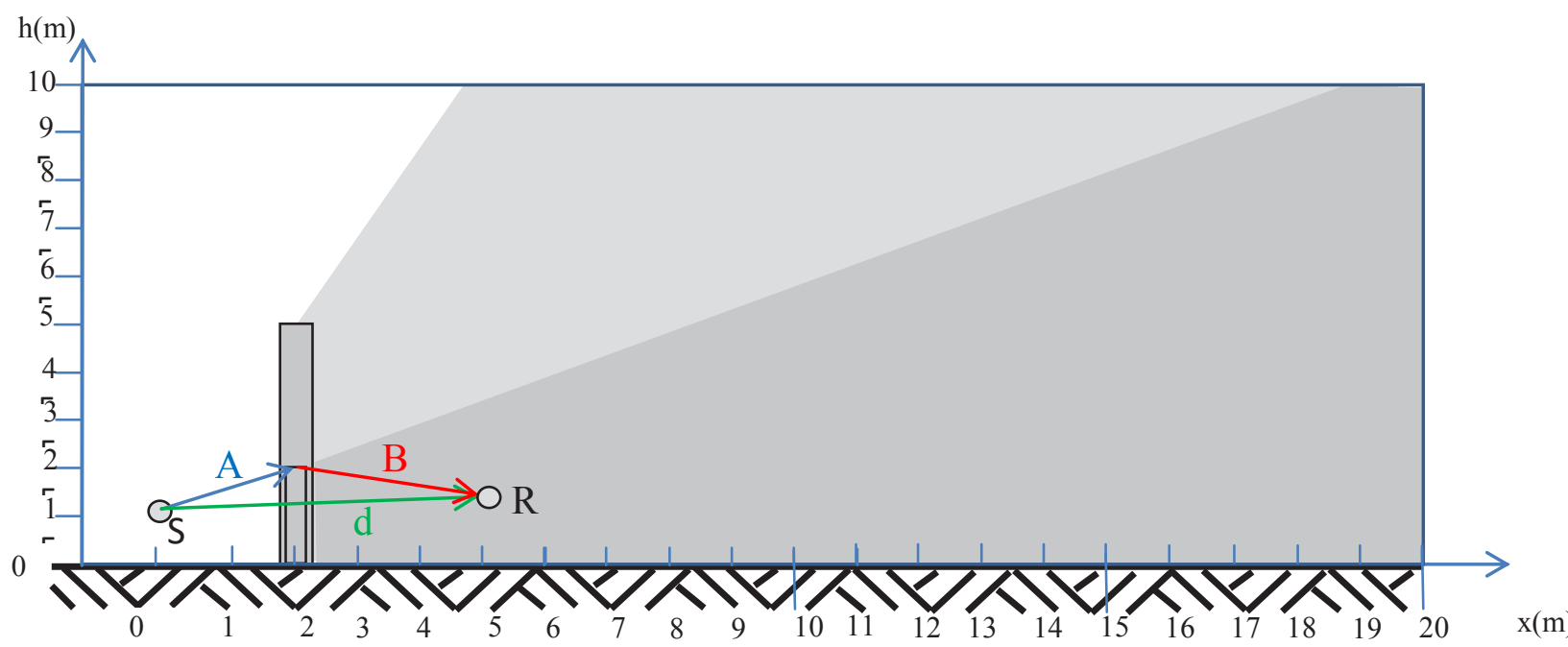

from the noise source (the shaded area in Figure 1). For any point in this area, the sound wave generated by the noise source suffers is diffracted at the top of the acoustic barrier. In this study, we analyze five different heights of the acoustic barrier (five different geometries) and for each height the protected area will be different.

Fig.1. 2D geometry for two acoustic barrier heights $(2 \mathrm{~m}$ and $5 \mathrm{~m})$ and the corresponding protected area

When no acoustic barrier is mounted the noise level in the protected area is due to the sound wave propagated directly from the noise source $(\mathrm{S})$ to the reception point (R), covering a distance d (m) (Fig. 1). After the installation of the acoustic barrier, the noise level is due to the diffracted wave, (the wave generated by the noise source $(\mathrm{S})$, and passing around the acoustic barrier at its highest point to reach the receiver point (R). Thus, the new distance covered by the diffracted sound wave, $A+B(m)$, where $A(m)$ is the distance from the source to the highest point of barrier and B $(\mathrm{m})$ is the distance from the highest point of the barrier to the receiver, is longer than if there were no acoustic barrier.

To determine the sound energy decrease due to a certain acoustic barrier, firstly we determine the Fresnel's number N (-) (Equation 1) [8].

$$
N=2 \cdot \frac{A+B-d}{\lambda},
$$

where $\lambda(m)$ is the sound wave length, (variable with the frequency). Further, the Maekawa theory will lead to assessment of the noise level attenuation in the reception point $\Delta L p(d B)$, compared to the case when there was no acoustic barrier, as a function of the Fresnel's number, $\mathrm{N}$.

In urban environment the noise source is an HVAC equipment that generates sound energy on all frequencies of the audible spectrum. Thus the Fresnel's number and further the noise level attenuation are different from one frequency to another. 
not protected by the acoustic barrier (outside the shaded area), a zero noise attenuation value was imposed (negative Fresnel's number is irrelevant for our application).

In order to obtain the abacuses for rapid calculation of the noise level attenuation, these attenuations were calculated for each receptor position inside the matrix, each height of the acoustic barrier and each frequency: $125 \mathrm{~Hz}$ and $250 \mathrm{~Hz}$ (low frequencies), $500 \mathrm{~Hz}$ and $1000 \mathrm{~Hz}$ (median frequencies) and $2000 \mathrm{~Hz}$ and $4000 \mathrm{~Hz}$ (high frequencies).

In Fig. 2, corresponding to the $125 \mathrm{~Hz}$ frequency, we can compare the effect of the five heights of acoustic barriers. We considered the HVAC equipment of a house representing the noise source while the facade of the closest building (block of flats) is the receptor. Inbetween the two buildings, at $2 \mathrm{~m}$ from the noise source the acoustic barriers are placed. In the case of the $1 \mathrm{~m}$ height barrier (Fig. 2a), the protected area is the narrowest and therefore such an acoustic barrier is appropriate for receiver points placed on the ground or below ground level (depending on the relief). The protection provided by this $1 \mathrm{~m}$ height barrier is $5-6 \mathrm{~dB}$ at ground level, representing a low noise protection.

For the $2 \mathrm{~m}$ height barrier (Fig. 2b), the protected area is larger and the attenuation of ground level noise is approximately 8-10 dB. For the $3 \mathrm{~m}$ height barrier (Fig. $2 \mathrm{c}$ ), the protected area is wider, and the attenuation of ground level noise is $12-15 \mathrm{~dB}$. For the $4 \mathrm{~m}$ high barrier,
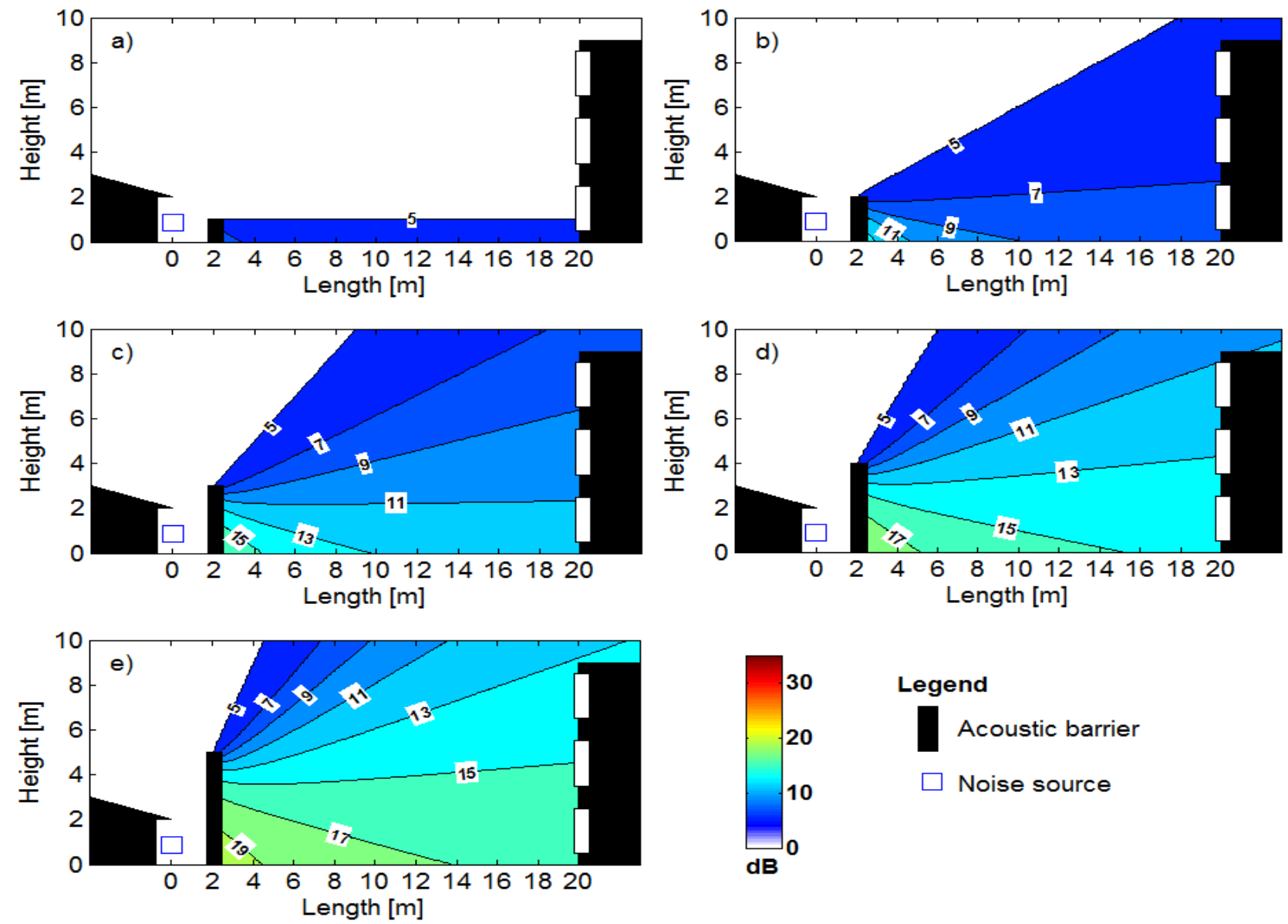

the attenuation of the ground level noise increases to 14 $17 \mathrm{~dB}$, and for the $5 \mathrm{~m}$ barrier height it reaches $16-19 \mathrm{~dB}$.

As a general trend it is noted that the higher the height of the barrier the larger the protected area and the higher the noise level attenuation.

The minimum values of the sound level attenuation (about $5 \mathrm{~dB}$ ) are found on the separation line between the area protected by the acoustic barrier (shaded area in Figure 1) and the unprotected area. Above this separation line, the attenuation rapidly descends to $0 \mathrm{~dB}$ (zone corresponding to negative Fresnel's number). In our study we considered the effect of the acoustic barrier is considered to be null.

The location where the sound level attenuation is highest is in the immediate vicinity of the barrier behind it. At this location, for the $1 \mathrm{~m}$ high barrier the attenuation is $7 \mathrm{~dB}$, while for the $5 \mathrm{~m}$ barrier the attenuation reaches $20 \mathrm{~dB}$.

If we consider a reception point at a horizontal distance of $20 \mathrm{~m}$ from the noise source and at a height of $5 \mathrm{~m}$ (located on the first floor of the block of flats) it is observed that the $1 \mathrm{~m}$ height barrier does not provide any protection whatever the frequency. But the $2 \mathrm{~m}$ barrier provides a $6.3 \mathrm{~dB}$ sound level attenuation at $125 \mathrm{~Hz}$ (Fig. 2b), a $3 \mathrm{~m}$ barrier assures a $10 \mathrm{~dB}$ attenuation, a $4 \mathrm{~m}$ barrier assures an attenuation of $13 \mathrm{~dB}$, and the $5 \mathrm{~m}$ barrier provides a $15 \mathrm{~dB}$ attenuation.

Fig. 2. Noise level attenuation at $125 \mathrm{~Hz}$ for an acoustic barrier height of: a) $1 \mathrm{~m}$; b) $2 \mathrm{~m}$; c) $3 \mathrm{~m}$; d) $4 \mathrm{~m}$; e) $5 \mathrm{~m}$ 

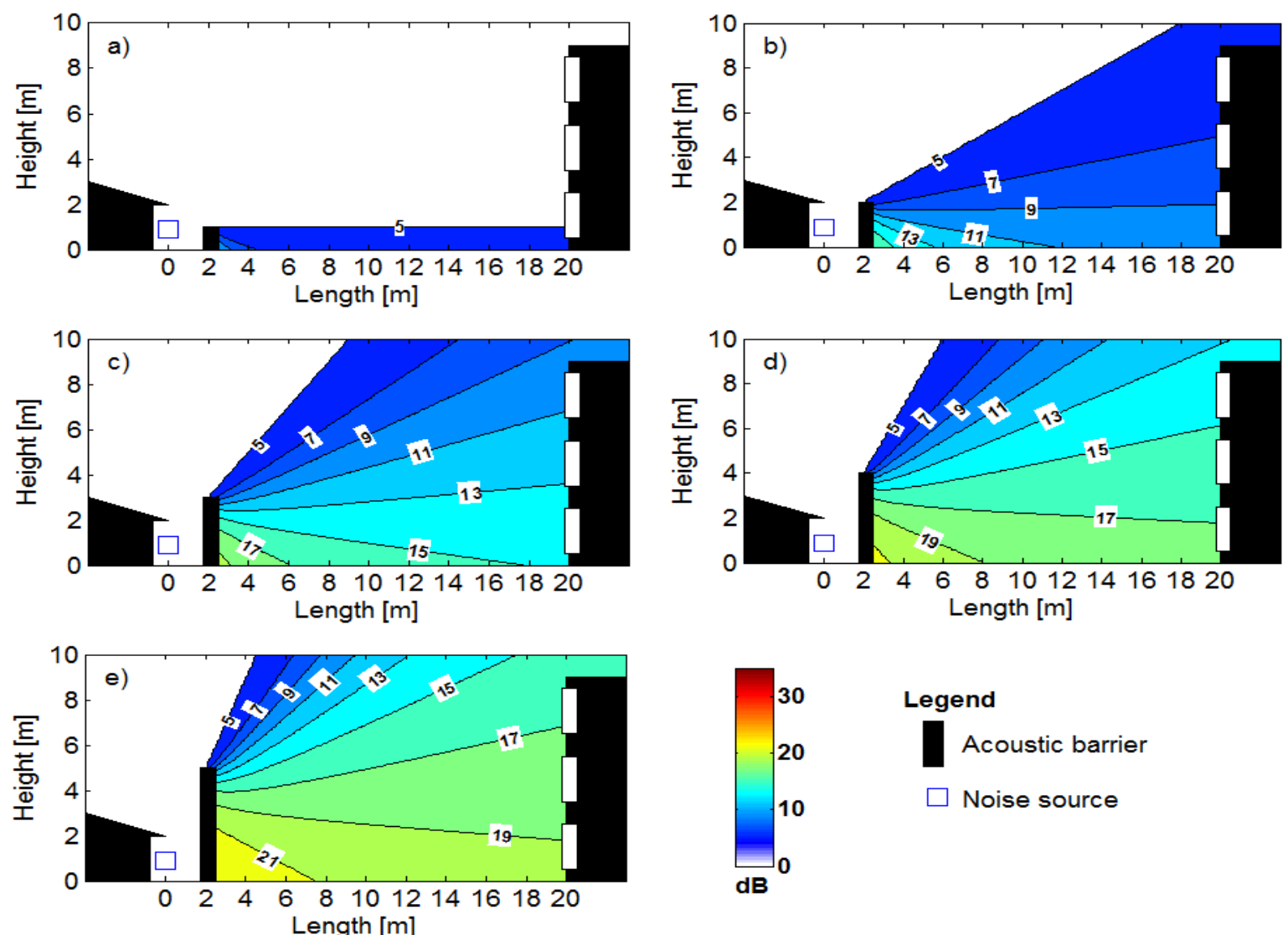

Fig. 3. Noise level attenuation at $250 \mathrm{~Hz}$ for an acoustic barrier height of: a) $1 \mathrm{~m}$; b) 2m; c) 3m; d) $4 \mathrm{~m}$; e) $5 \mathrm{~m}$
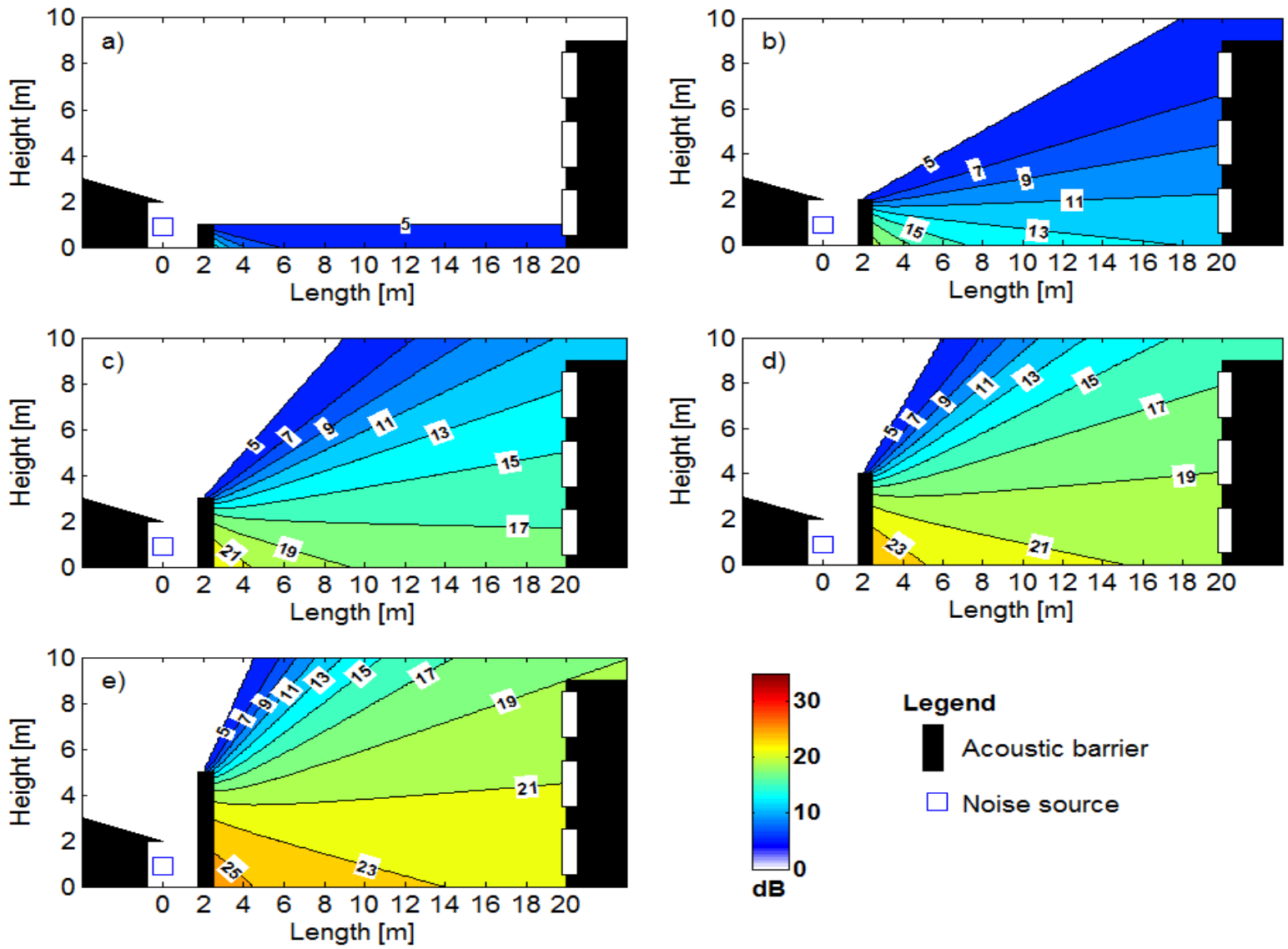

Legend

Acoustic barrier

$\square$ Noise source

Fig. 4. Noise level attenuation at $500 \mathrm{~Hz}$ for an acoustic barrier height of: a) $1 \mathrm{~m}$; b) $2 \mathrm{~m}$; c) $3 \mathrm{~m}$; d) 4m; e) $5 \mathrm{~m}$ 

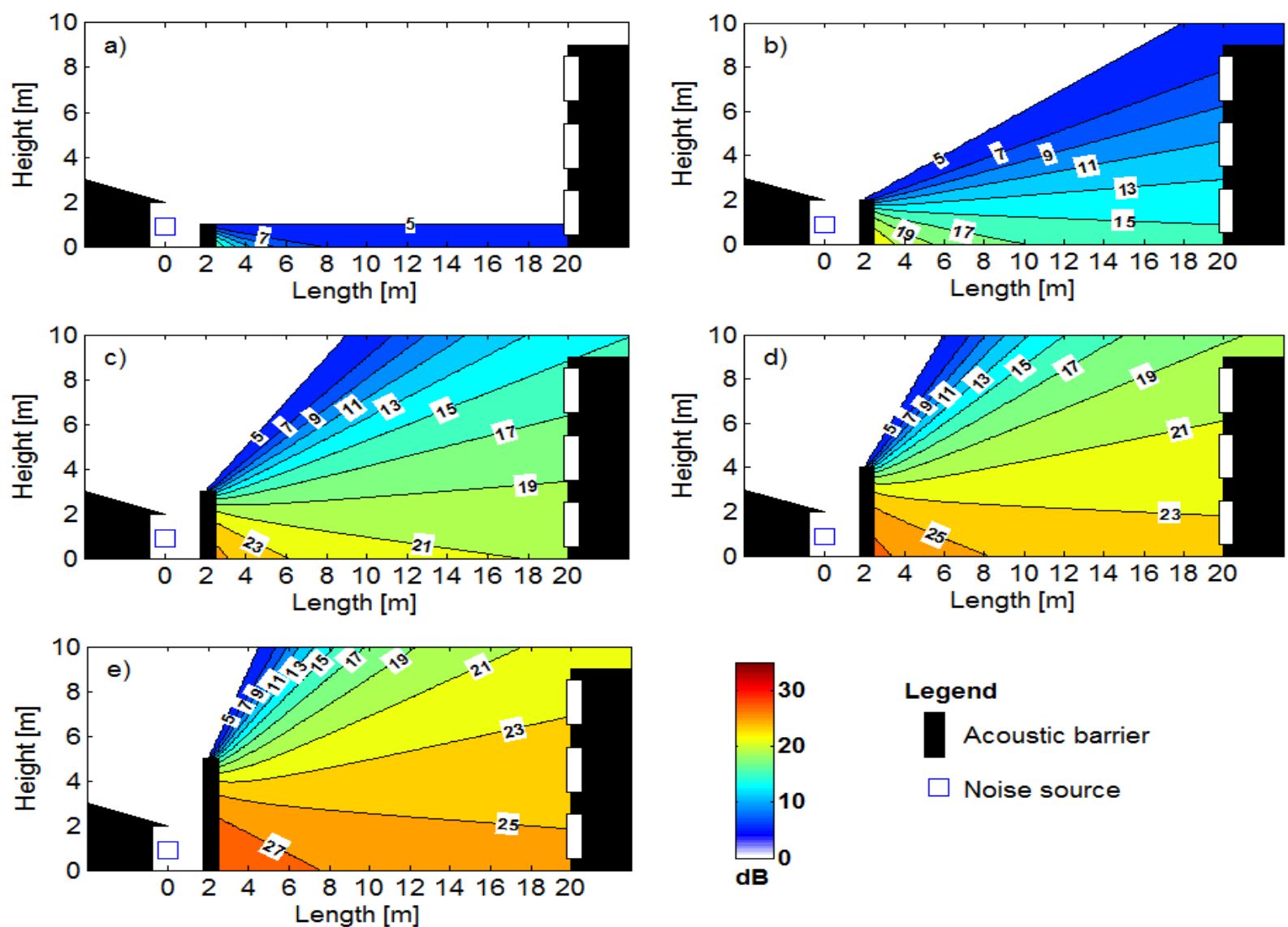

Fig. 5. Noise level attenuation at $1000 \mathrm{~Hz}$ for an acoustic barrier height of: a) 1m; b) 2m; c) 3m; d) 4m; e) $5 \mathrm{~m}$
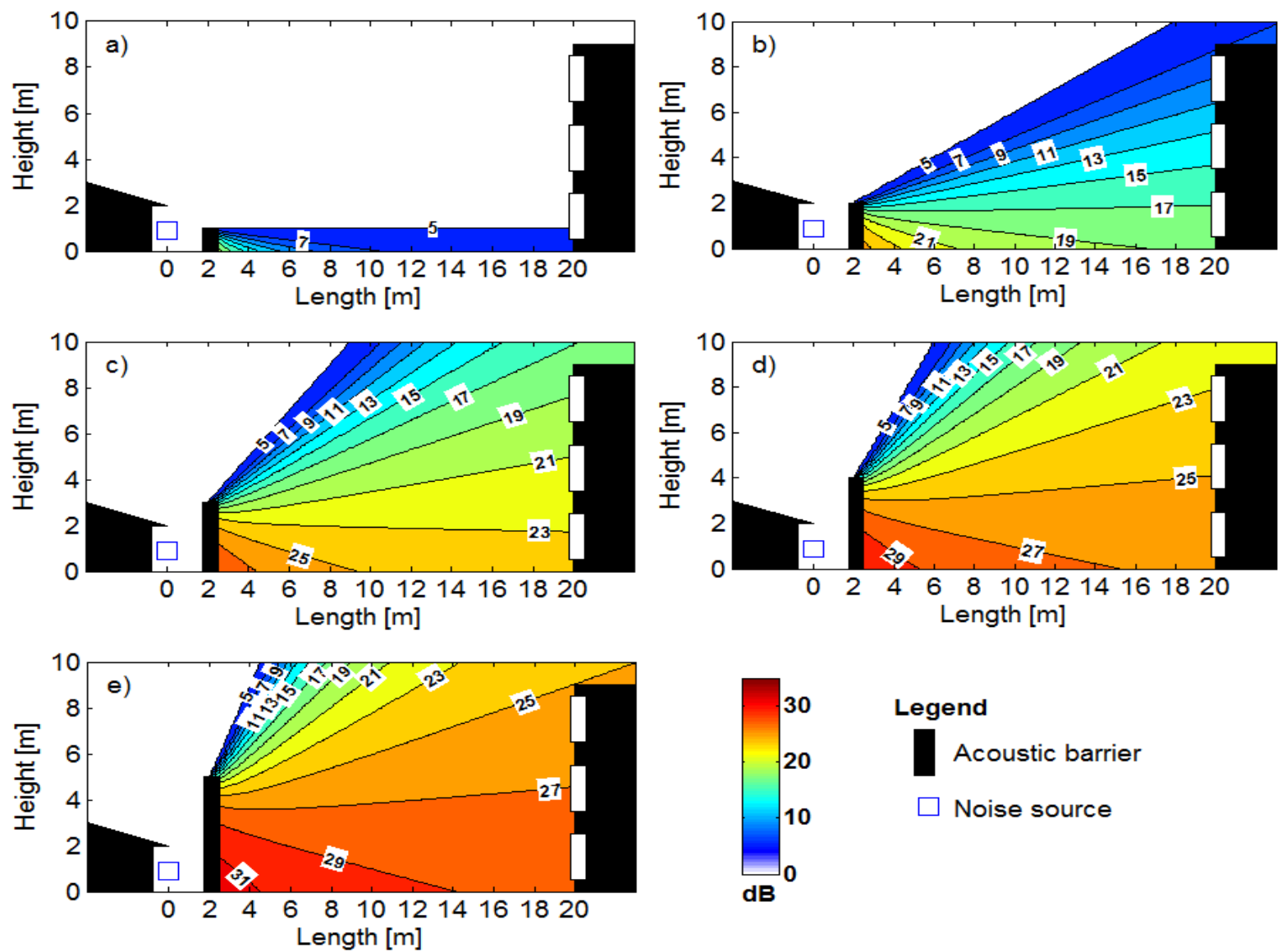

\section{Legend}

Acoustic barrier

$\square$ Noise source

Fig. 6. Noise level attenuation at $2000 \mathrm{~Hz}$ for an acoustic barrier height of: a) 1m; b) 2m; c) 3m; d) 4m; e) $5 \mathrm{~m}$ 

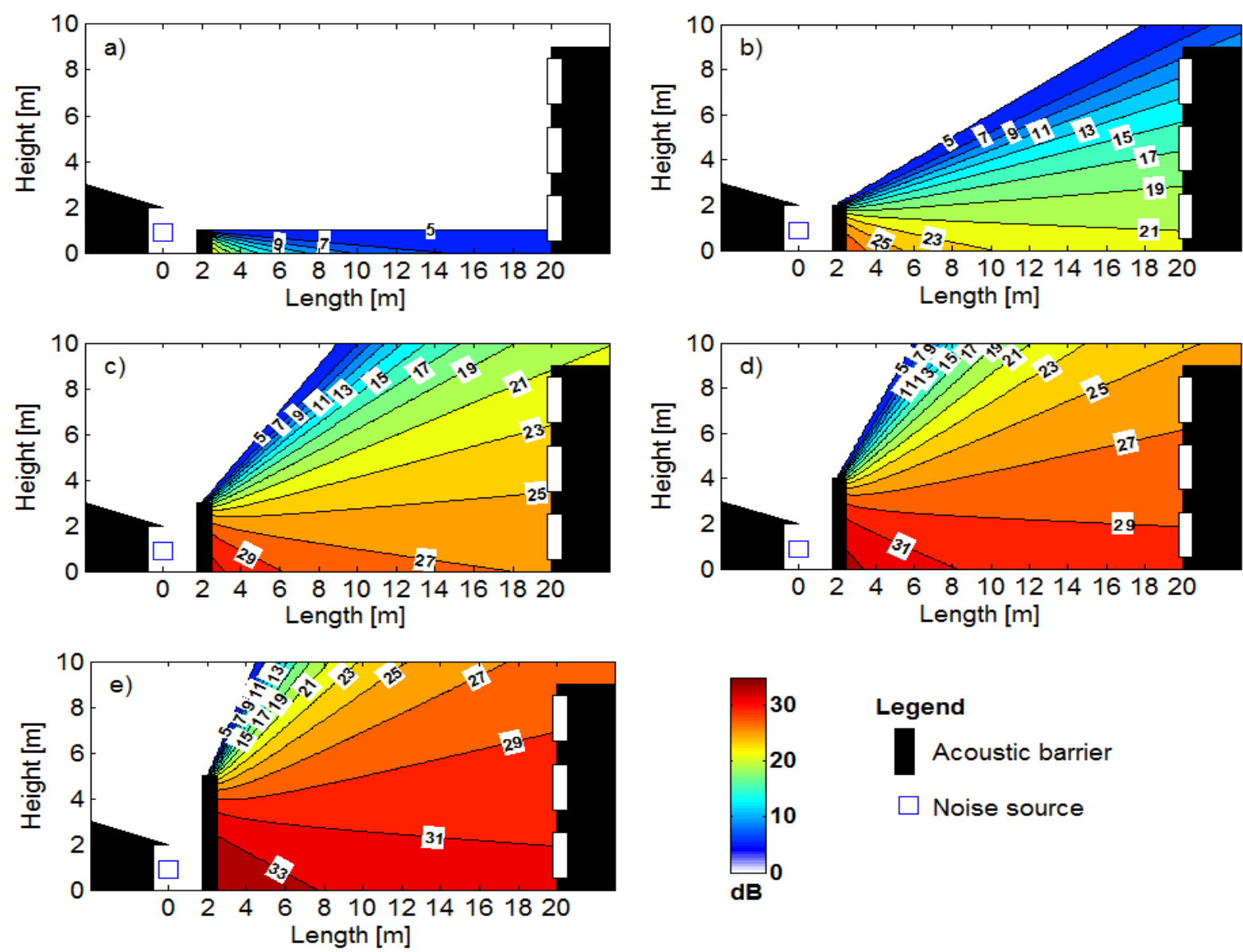

Fig. 7. Noise level attenuation at $4000 \mathrm{~Hz}$ for an acoustic barrier height of: a) 1m; b) 2m; c) 3m; d) $4 \mathrm{~m}$; e) $5 \mathrm{~m}$

In Fig. 3, corresponding to the $250 \mathrm{~Hz}$ frequency, the same general tendency is observed: the higher the barrier height, the higher the protected area and the higher the sound level attenuation. The maximum attenuation corresponding to the $5 \mathrm{~m}$ height acoustic barrier is about $23 \mathrm{~dB}$, higher than the maximum attenuation corresponding to the $125 \mathrm{~Hz}$ frequency (20dB). For a receiver located $18 \mathrm{~m}$ behind the acoustic barrier and $2 \mathrm{~m}$ high, the $2 \mathrm{~m}$ height barrier sound level attenuation at $250 \mathrm{~Hz}$ is about $7.5 \mathrm{~dB}$.

In Fig.4 - 7, corresponding to frequencies $500 \mathrm{~Hz}$, $1000 \mathrm{~Hz}, 2000 \mathrm{~Hz}$ and $4000 \mathrm{~Hz}$ respectively, the same general tendency is observed: the higher the barrier height, the higher the protected area and the higher the sound level attenuation. The maximum attenuation is met behind the acoustic barrier for all frequencies.

Moreover, the sound level attenuation is variable as a function of the frequency: the higher the frequency the higher the attenuation. Thus, for $4000 \mathrm{~Hz}$ the highest attenuation is about $34 \mathrm{~dB}$ compared to only $20 \mathrm{~dB}$ corresponding to $125 \mathrm{~Hz}$.

\section{Study case}

This chapter exemplifies how these simplified abacuses can be used to correctly design the height of an acoustic barrier. We shall consider the case of a rooftop ventilation equipment placed of the flat roof of an office building (marked "OB" in Fig. 8), which represents the sound source (marked with " $\mathrm{S}$ " in Fig. 8) placed at $2 \mathrm{~m}$ from the office building attic. The reception point (marked with R in Fig. 8) is represented by the window of the nearby apartment building (marked "AB" in Fig. 8) where the façade maximum allowed noise level is 45 $\mathrm{dB}$ at $1000 \mathrm{~Hz}$. The distance between the rooftop and the analyzed window is $10 \mathrm{~m}$ and the acoustic pressure level on the façade of the apartment building is $59.5 \mathrm{~dB}$, thus it is $14.5 \mathrm{~dB}$ over the maximum allowable limit. We note the higher the distance between the receiver and the sound source, the smaller the noise level in the receiver point. This is due to the dispersion of the sound energy emitted by the rooftop all-around into a sphere shape and thus the further the reception point from the source the higher the surface area of the sphere where the energy is dispersed (Fig. 8a).

An acoustic barrier would be installed close to the attic of the office building (blue line in Fig. 8) at $2 \mathrm{~m}$ away from the noise source and at $8 \mathrm{~m}$ from the reception point. This barrier would alter this spherical energy dispersion behind the acoustic barrier.

We will consider the initial height of the acoustic barrier to be $1 \mathrm{~m}$. Thus for a $1000 \mathrm{~Hz}$ frequency we will use the abacus in Fig. 5a and the sound level attenuation is about $6 \mathrm{~dB}$. Consequently, the noise level after the installation of the acoustic barrier is about $54 \mathrm{~dB}$ (Fig. $8 b)$. The attenuation on the façade of the apartment building is variable (lower acoustic pressure levels for lower floors of the apartment building façade), but for our reception point the noise protection condition is not fulfilled. For the case of the $2 \mathrm{~m}$ height acoustic barrier

* Corresponding author: viordach@yahoo.com 
(attenuation abacus in Fig. 5b) the attenuation is $15 \mathrm{~dB}$, and thus the acoustic prresure level is $44.5 \mathrm{~dB}$ (Fig. 8c) and the maximum limit condition is fulfilled.
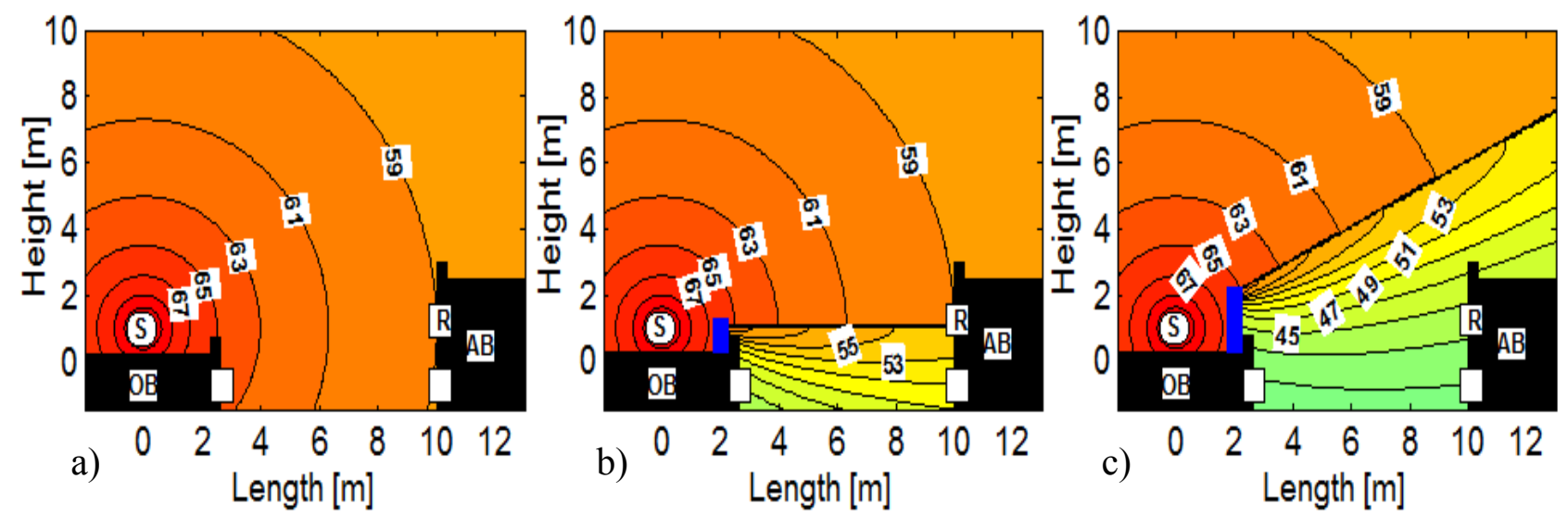

Fig. 8. Noise level comparison at $1000 \mathrm{~Hz}$ betwen three situations: a) no acoustic barrier, b) acoustic barrier height $1 \mathrm{~m}$, c) acoustic barrier height $2 \mathrm{~m}$

\section{Conclusions}

The Maekawa method of calculating the noise attenuation characteristic of an acoustic barrier has been applied to several receptor positions in the shaded area. The results were used to create simplified abacuses for the sizing of the acoustic barrier height. The abacuses were built for five types of barrier heights from $1 \mathrm{~m}$ to 5 $\mathrm{m}$ and for different frequencies from 125 to $4000 \mathrm{~Hz}$.

The study case proves that these abacuses essentially contribute to simplifying the height sizing calculation of an acoustic barrier while maintaining the same precision as the classical method.

Moreover, this study also represents a validation of this approach in order to achieve other simplifying methods for other geometries and special cases where the classical method can also become difficult to apply.

\section{Acknowledgement}

This study is supported by Romanian Authority for Scientific Research and Innovation, CNCS/CCCDI UEFISCDI, through research project PN-III-P2-2.1PED-2016-1951.

\section{References}

[1] SR 10009:2017 - Acustică. Limite admisibile ale nivelului de zgomot din mediul ambiant.

[2] Z. Maekawa, "A simple estimation method for noise reduction by various shaped barriers," Revista de Acustica, vol. XXI, pp. 32-37, 1990.

[3] K. W. W. H. Kasess CH, "Deriving correction functions to model the efficiency of noise barriers with complex shapes using boundary element simulations.," Applied Acoustics, vol. 102, pp. 88-99, 2016.

[4] U. J. Kurze and G. S. Anderson, "Sound attenuation by barriers," Applied Acoustics, vol. 4, no. 1, pp. 3553, 1971.

Corresponding author: viordach@yahoo.com
[5] Y. M. Lam, "Using Maekawa's chart to calculate finite length barrier insertion loss," Applied Acoustics, vol. 42, no. 1, pp. 29-40, 1994.

[6] Z. Maekawa, "Noise reduction by screens," Applied Acoustics, vol. 1, no. 3, pp. 157-173, 1968.

[7] "Normativ C125:2012 - Normativ privind acustica în constructii și zone urbane".

[8] R. Peng and L. Tang, "Narrowing effect of focused polychromatic laser with small Fresnel number," Optics Communications, pp. 2707-2710, 2011.

[9] "SR 6161-1:2008 Acustica în construcții. Partea 1: Măsurarea nivelului de zgomot în construcții civile. Metode de măsurare". 